\title{
Comparison of demographics, treatment patterns, health care utilization, and costs among elderly patients with extensive-stage small cell and metastatic non-small cell lung cancers
}

Sudeep J Karve ${ }^{1}$, Gregory L Price ${ }^{2}$, Keith L Davis ${ }^{1 *}$, Gerhardt M Pohl², Emily Nash Smyth² and Lee Bowman²

\begin{abstract}
Background: Limited data exist regarding real-world treatment patterns, resource utilization, and costs of extensive-stage small cell lung cancer (esSCLC) among elderly patients in the United States. While abundant data are available on treatment patterns in metastatic non-small cell lung cancer (mNSCLC), to our knowledge no data exist comparing costs and resource use between patients with esSCLC or mNSCLC.

Methods: We retrospectively analyzed administrative claims data (2000-2008) of patients aged $\geq 65$ years from the linked Surveillance, Epidemiology and End Results (SEER)-Medicare database. Patients were selected on the basis of having newly diagnosed esSCLC $(n=5,855)$ or $\operatorname{mNSCLC}(n=24,090)$ during 1/1/2000-12/31/2005, and were required to have received cancer-directed therapy. Survival and other measures were compared between esSCLC and mNSCLC patients using Kaplan-Meier log-rank and univariate chi-square and t-tests. Study measures were followed from first diagnosis date of either esSCLC or mNSCLC until the earlier of death or end of the database.

Results: Survival between the cohorts did not differ significantly: mean of 10.4 months for esSCLC patients versus 11.1 months for mNSCLC; median survival was 7.4 months versus 5.9 months. A higher percentage of mNSCLC patients (vs. esSCLC) received radiation therapy (75.6\% vs. 65.4\%; $P<0.001)$ and surgery $(13.6 \%$ vs. $7.8 \% ; P<0.001)$ during the metastatic disease period. Conversely, a higher percentage of esSCLC patients than $\mathrm{MNSCLC}$ patients received chemotherapy ( $85.5 \%$ vs. $60.3 \%$; $P<0.001)$, red blood-cell transfusion $(20.7 \%$ vs. $10.9 \%$; $P<0.001)$, platelet transfusion (5.6\% vs. 1.8\%; $P<0.001$ ), and growth-factor support (59.0\% vs. 39.5\%; $P<0.001)$. esSCLC patients incurred higher lifetime disease-related costs $(\$ 44,167$ vs. $\$ 37,932 ; P<0.001)$ and all-cause costs $(\$ 70,549$ vs. $\$ 67,176 ; P<0.001)$ than mNSCLC patients.
\end{abstract}

Conclusions: Lifetime total and disease-related costs per patient were high. Increased use of chemotherapy, supportive care therapies (including growth factors), and disease-related hospitalizations were observed in esSCLC patients as compared with mNSCLC patients. Disease-related and all-cause costs for esSCLC also exceeded those of mNSCLC, except for hospice and skilled nursing services. Survival and per-patient costs for both groups underscore the unmet medical need for more effective therapies in patients with esSCLC or mNSCLC.

Keywords: Metastatic lung cancer, Health care utilization, Health care costs, SEER-medicare

\footnotetext{
*Correspondence: kldavis@rti.org

'RTI Health Solutions, 3040 Cornwallis Road, Research Triangle Park, Durham, NC 27709, USA

Full list of author information is available at the end of the article
} 


\section{Background}

Lung cancer remains the second most commonly diagnosed cancer in the United States (US), with approximately 225,000 new cases and 160,000 deaths expected in 2014 [1]. Approximately $14 \%$ of new diagnoses are classified as having small cell lung cancer (SCLC), while the remaining $85 \%$ of cases are non-small cell lung cancer (NSCLC) [2]. Nearly two-thirds of these patients are diagnosed at age 65 years or older, with an estimated median age at diagnosis of 70 years [2]. Approximately 70\% of SCLC and $54 \%$ of NSCLC cases have metastasized to other organs at initial diagnosis; this higher percentage of SCLC patients diagnosed with extensive-stage disease (esSCLC) likely contributes to its lower overall 5-year survival rate (6.2\%) versus that of mNSCLC (18.0\%) [2].

For patients with mNSCLC, current and previous guidelines recommend platinum-doublet chemotherapy as first-line systemic treatment, although recommendations of specific agents and/or combinations of agents have evolved over time depending on disease histology (squamous or non-squamous) and, more recently, presence of epidural growth factor receptor (EGFR) and/or anaplastic lymphoma kinase (ALK) gene mutations [3]. For patients with esSCLC, etoposide plus a platinum agent (cisplatin or carboplatin) is the recommended first-line systemic therapy [4]. For both lung cancer types, radiotherapy may also be indicated either in sequential or concurrent use with chemotherapy $[3,4]$.

Lung cancer exerts a significant economic burden on the US health care system. A recent study estimated that in 2010, medical costs related to lung cancer were $\$ 12.1$ billion and were expected to increase to $\$ 15.2$ billion by 2020 [5]. Because the median age atf diagnosis in lungcancer patients is high (71 years) [2], this cost burden is largely incurred by the US Medicare system. Despite this burden and its expected future trend, limited data exist comparing health care resource use and costs in elderly patients with either esSCLC or mNSCLC [6,7]. Additonally, to our knowledge, there are no data describing treatment patterns for esSCLC.

Most existing cost studies focus on mNSCLC alone [8-10] or on all lung cancers combined [11-13]. Existing cost studies have primarily focused on estimations of chemotherapy use and costs [14-17], with little information presented regarding broader treatment patterns, resource utilization, and costs for other service categories. Only one recently published US study addressed these knowledge gaps, although the authors used data drawn from 1992 to 2003 [18].

To help meet these information needs, we conducted a retrospective analysis of the linked Surveillance, Epidemiology and End Results (SEER)-Medicare database to provide a summary of trends in treatment patterns, and a comparison of health care resource utilization and direct health care costs among elderly Medicare enrollees with esSCLC and mNSCLC.

\section{Methods}

\section{Data source}

The SEER program, initiated by the National Cancer Institute in 1973, collects cancer incidence and survival data from population-based registries covering approximately $28 \%$ of the US population [19]. In this retrospective longitudinal cohort study, we analyzed the SEER-Medicare linked database from 2000 through 2008. At the time this study was conducted, the SEER-Medicare database included new cancer cases first diagnosed through 2005, with linked claims data available on these subjects through 2008 .

The data files utilized for this analysis were those included in the standard SEER-Medicare file set available from the NCI: Patient Entitlement and Diagnosis Summary File (PEDSF); Medicare Provider Analysis and Review (MEDPAR) hospital file; Carrier Claims (physician office visits) file; Outpatient (other ambulatory care) file; Home Health Agency (home health services) file; Hospice file; and Durable Medical Equipment file.

The conduct of this study was approved by an authorized institutional review board: the Research Triangle Institute (RTI) Committee on the Protection of Human Subjects (Federal-Wide Assurance [FWA] \#3331) is registered with the US Department of Health and Human Services (DHHS) Office for Human Research Protections (OHRP).

\section{Patient selection}

Patients with a new lung cancer diagnosis (International Classification of Diseases for Oncology, Third Edition [ICD-O-3] topography codes: C34.0-C34.9) between January 1, 2000, and December 31, 2005, were selected for initial inclusion. These patients were classified as SCLC or NSCLC, using ICD-O-3 histology codes 8041-8045 for SCLC and 8046 for NSCLC [20]. We further restricted the sample to patients with extensivestage and metastatic disease (esSCLC or mNSCLC) at diagnosis, using tumor staging information provided in the SEER data. Details on SEER cancer staging classifications are provided elsewhere [21]. For all selected patients, the study index date was defined as the date of the first SEER-reported diagnosis of esSCLC or mNSCLC. Furthermore, the study cohort was limited to patients who received cancer-directed therapy (surgery, radiation, chemotherapy, biologic therapy) at some point on or after their index date. All patients were required to be 65 years of age or older at first diagnosis and to have age as their reason for Medicare eligibility. Patients also were required to have at least 6 months of continuous Medicare enrollment prior to their study index date. 
Patients were followed from the index date until the earlier of death or end of the database. A minimum post-index follow-up duration was not required for study inclusion. Patients enrolled in a health maintenance organization during the 6-month pre-index period or at any time during post-index follow-up were excluded $[22,23]$. Finally, we excluded patients with evidence of other malignancies at any point pre- or post-index, except for basal and squamous cell carcinomas of the skin which are not reportable to SEER.

\section{Study measures}

\section{Patient characteristics}

Background characteristics of age, sex, race, US Census region of residence, urban versus rural location of residence, and tumor histology were evaluated. Underlying comorbidity burden was assessed using the Charlson Comorbidity Index score (excluding diagnosis codes for lung cancer) with the Deyo adaptation for claims data [24].

\section{Treatment patterns}

Treatment patterns associated with esSCLC and mNSCLC, including supportive and palliative therapies, were defined by the relevant Health Care Financing Administration Common Procedure Coding System (HCPCS), International Classification of Diseases, Ninth Revision, Clinical Modifications (ICD-9-CM) procedure codes, and certain ICD-9-CM diagnostic codes and administrative revenue codes (see Additional file 1) recorded in the linked Medicare claims data.

We documented detailed usage patterns of chemotherapy including the most frequently observed first-, second-, and third-line chemotherapy regimens. Specific regimen compositions were defined by using algorithms developed in previous claims-based studies of chemotherapy utilization $[9,14]$. For first-, second-, and third-line chemotherapy regimens, we assessed the number of treatment cycles that were administered to each patient by using methods presented in recent claims-based cancer studies by Ramsey et al. [13] and Weycker et al. [25].

\section{Health care utilization and costs}

Total all-cause and disease-related health care utilization as well as costs were aggregated for each patient across the entire available follow-up period and stratified by major care settings: inpatient, outpatient, emergency department, physician office, skilled nursing facility, hospice, and other ancillary care. Disease-related health care utilization and associated costs were defined as claims for cancer-directed treatment or medical encounters or discharge records for inpatient admission carrying a lung cancer ICD-9-CM diagnosis code [16,26].

Medicare-reimbursed amounts provided on each unique claim in the database were used to assess all-cause and disease-related costs. To approximate total lifetime costs, all cost data associated with the selected service categories were aggregated and reported as per-patient total costs across all available follow-up, from study index date until the earlier death or end of the database (December 31, 2008). Costs were inflated at the claim level to 2010 US dollars using the medical component of the US Consumer Price Index.

\section{Statistical analyses}

Descriptive statistics that were generated for all analysis variables included frequency distributions for categorical variables, and mean values and standard deviations (SDs) for continuous variables. The statistical significance of unadjusted differences in the outcomes of interest between patient cohorts (esSCLC vs. mNSCLC) was measured using Student t-tests and chi-square tests, as appropriate. Kaplan-Meier survival curves and corresponding log-rank tests were used to compare differences in survival time by cancer type. Among patients who died during follow-up, survival time was defined as the number of months between the study index date and the date of death. Among patients who did not die during follow-up, survival time was censored at the end of the database.

\section{Results}

\section{Patient characteristics}

A total of 29,945 patients met all study inclusion criteria: 5,855 (19.6\%) of whom had esSCLC and 24,090 (80.4\%) had mNSCLC (Figure 1). Patients differed statistically $(P<0.001)$ across all demographic characteristics between the two lung-cancer types (Table 1). The majority of patients in both cohorts were between the ages of 65 and 74 years; esSCLC patients on average were slightly younger than those with mNSCLC (73.5 vs. $74.4 ; \mathrm{p}<0.001)$. A greater number of patients in both cohorts were male, white, and were more likely to be located in the western part of the US in large metropolitan areas. Approximately $20 \%$ of patients with mNSCLC had tumors of squamous histology, while $41 \%$ had adenocarcinomas. While there were statistical differences, the co-morbidity status (measured by mean Charlson score) of both groups were comparable (esSCLC: 1.6 [SD: 1.9] vs mNSCLC: 1.4 [SD 1.9]). Nearly all patients (approximately 99\%) from both study groups died during the follow-up period. Survival time between the cohorts did not differ significantly (logrank: $P=0.424)$ : mean [standard error] survival was 10.4 [0.2] months for esSCLC patients versus 11.1 [0.1] months for mNSCLC patients; median survival was 7.4 months (interquartile range [IQR]: 3 - 12.5) versus 5.9 months (IQR: 2.9 - 12.5), respectively (Figure 2). 


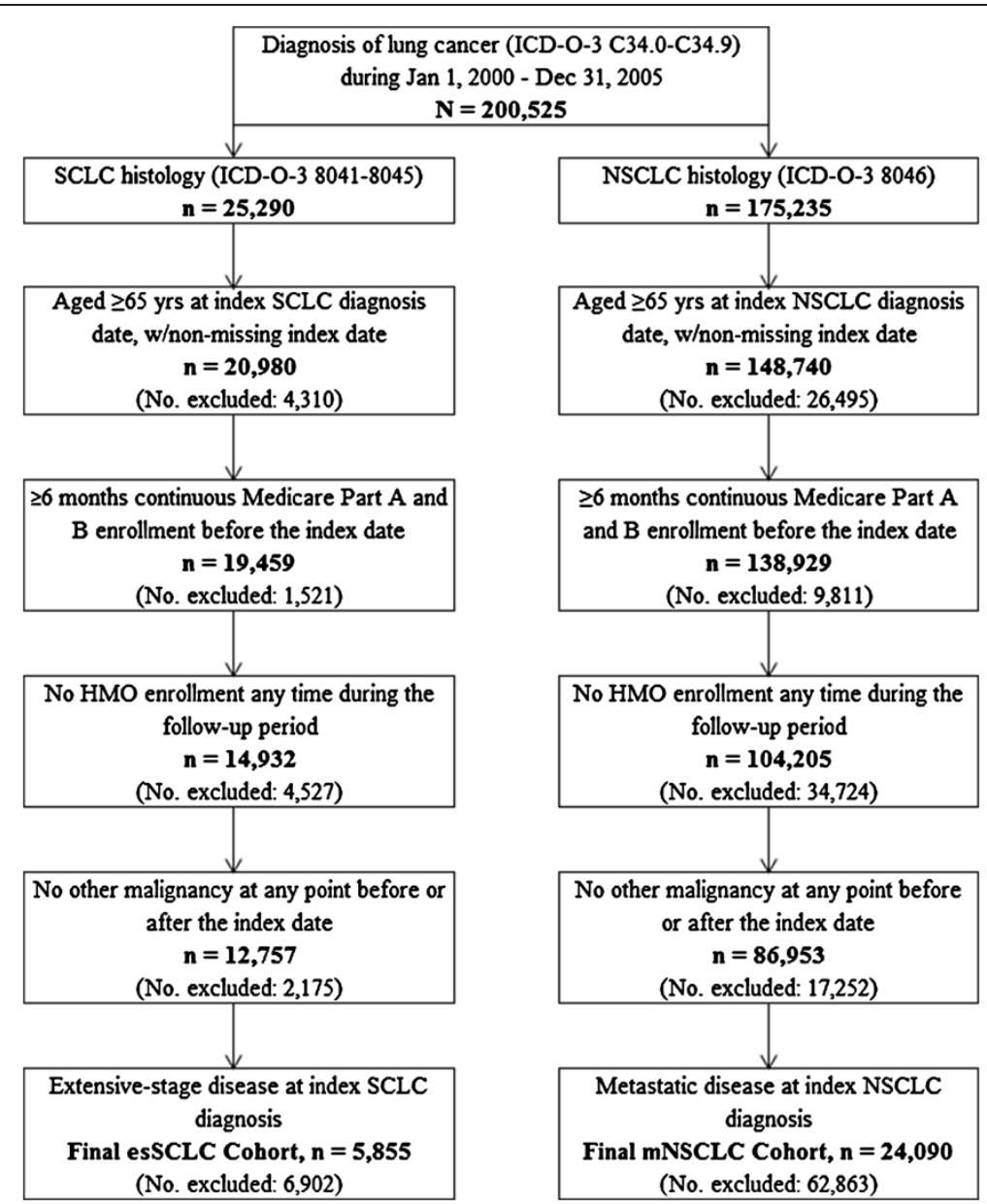

Figure 1 Sample attrition chart. $\mathrm{mNSCLC}=$ metastatic non-small cell lung cancer; esSCLC = extensive-stage small cell lung cancer.

\section{Treatment patterns}

Chemotherapy use was significantly more prevalent in esSCLC patients than in mNSCLC patients $(85.4 \%$ vs. 60.3\%; $P<0.001$ ) (Table 2), and fewer esSCLC patients received surgery $(7.8 \%$ vs. $13.6 \% ; P<0.001)$ and radiation therapy $(65.4 \%$ vs. $75.6 \% ; P<0.001)$. Approximately $46.7 \%$ of esSCLC patients and $32.4 \%$ of mNSCLC patients received both radiation and chemotherapy during the follow-up period $(P<0.001)$. Radiation plus chemotherapy was the only combination treatment approach seen with substantial frequency in either cohort. Overall, the proportion of patients receiving biologic therapy, which included interleukin and interferon, was low in both the esSCLC (1.8\%) and mNSCLC (1.2\%) cohorts.

Among esSCLC patients initiating chemotherapy, etoposide plus either carboplatin or cisplatin was the most frequently observed first-line regimen, with a mean of 3.7 (carboplatin plus etoposide) and 3.4 (cisplatin plus etoposide) total cycles administered (Figure 3). Of all esSCLC patients receiving first-line chemotherapy, 43.2\% received a second-line regimen and $18.0 \%$ received a third-line regimen. Monotherapy with intravenous topotecan was the most common regimen seen in second-line (26.3\%) and third-line initiators (20.8\%) with esSCLC.

A carboplatin-based regimen was the most common first-line therapy initiated in mNSCLC patients (65.6\%) with carboplatin plus paclitaxel being the most frequently used (44.0\%) combination, with a mean of 3.3 cycles administered. Among mNSCLC patients initiating a firstline regimen, $22.6 \%$ subsequently received second-line therapy and $8.8 \%$ received third-line therapy. The most commonly used second- and third-line regimens included docetaxel (20.2\%) and vinorelbine monotherapy (16.1\%). Utilization of supportive and other palliative therapies during the follow-up period are presented in Table 2 . A significantly higher proportion of esSCLC patients received growth-factor therapy than did mNSCLC patients $(59.0 \%$ vs. $39.5 \% ; P<0.001)$. Among patients who required growth-factor support, erythropoietin (40.1\%), filgrastim (25.1\%), and pegfilgrastim (21.6\%) were the most commonly used agents for esSCLC patients. For mNSCLC patients, erythropoietin (28.4\%), darbepoetin 
Table 1 Baseline esSCLC and mNSCLC patient characteristics

\begin{tabular}{|c|c|c|c|}
\hline & \multicolumn{2}{|l|}{ Study groups } & \multirow[t]{2}{*}{$P$ value } \\
\hline & esSCLC & mNSCLC & \\
\hline Overall, (n, \%) & $5,855(100.0)$ & $24,090(100.0)$ & - \\
\hline \multicolumn{4}{|l|}{ Age } \\
\hline Mean (SD) & $73.5(5.6)$ & $74.4(6.0)$ & $<0.001$ \\
\hline \multicolumn{4}{|l|}{ Age group, n (\%) } \\
\hline $65-74$ years & $3,474(59.3)$ & $12,911(53.6)$ & \multirow[t]{3}{*}{$<0.001$} \\
\hline $75-84$ years & $2,170(37.1)$ & $9,749(40.5)$ & \\
\hline$\geq 85$ years & $211(3.6)$ & $1,430(5.9)$ & \\
\hline \multicolumn{4}{|l|}{ Gender, n (\%) } \\
\hline Male & $2,998(51.2)$ & $13,535(56.2)$ & \multirow[t]{2}{*}{$<0.001$} \\
\hline Female & $2,857(48.8)$ & $10,555(43.8)$ & \\
\hline \multicolumn{4}{|l|}{ Race, n (\%) } \\
\hline White & $5,243(89.6)$ & $20,519(85.2)$ & \multirow[t]{3}{*}{$<0.001$} \\
\hline Black & $376(6.4)$ & $2,102(8.7)$ & \\
\hline Other/unknown & $236(4.0)$ & $1,469(6.1)$ & \\
\hline \multicolumn{4}{|l|}{ Census region, n (\%) } \\
\hline Northeast & $1,303(22.3)$ & $5,620(23.3)$ & \multirow[t]{4}{*}{$<0.001$} \\
\hline Midwest & $941(16.1)$ & 3,521 (14.6) & \\
\hline South & $1,482(25.3)$ & $5,397(22.4)$ & \\
\hline West & $2,129(36.4)$ & $9,552(39.7)$ & \\
\hline \multicolumn{4}{|c|}{ Urban/rural status of residency, n (\%) ${ }^{a}$} \\
\hline Big metro & $3,029(51.7)$ & $13,331(55.3)$ & \multirow[t]{5}{*}{$<0.001$} \\
\hline Metro & $1,708(29.2)$ & $6,905(28.7)$ & \\
\hline Urban & $409(7.0)$ & $1,568(6.5)$ & \\
\hline Less urban & $566(9.7)$ & $1,865(7.7)$ & \\
\hline Rural & $143(2.4)$ & $421(1.8)$ & \\
\hline \multicolumn{4}{|l|}{ Tumor histology, n (\%) } \\
\hline \multicolumn{4}{|l|}{ esSCLC cases } \\
\hline Small cell carcinoma & $5,855(100.0)$ & - & - \\
\hline \multicolumn{4}{|l|}{ mNSCLC cases } \\
\hline Squamous cell & - & $4,865(20.2)$ & - \\
\hline Adenocarcinoma & - & $9,816(40.7)$ & - \\
\hline Large Cell & - & $1,363(5.7)$ & - \\
\hline Other specified carcinomas & - & $316(1.3)$ & - \\
\hline Carcinomas unspecified & - & $7,730(32.1)$ & - \\
\hline \multicolumn{4}{|l|}{ Charlson comorbidity index score } \\
\hline Mean (SD) & $1.6(1.9)$ & $1.4(1.9)$ & $<0.001$ \\
\hline
\end{tabular}

mNSCLC = metastatic non-small cell lung cancer; esSCLC = extensive-stage small cell lung cancer; SD = standard deviation.

${ }^{a}$ Urban/rural definitions per SEER registry: Big Metro = counties in metro areas of $>1$ million population; Metro = counties in metro areas of $\leq 1$ million population; Urban $=$ areas of $\geq 20,000$ population adjacent/non-adjacent to (but not in) a metro area; Less Urban $=$ areas of $<20,000$ population adjacent/non-adjacent to (but not in) a metro area; Rural = completely rural or urban population $<2,500$ adjacent/non-adjacent to (but not in) a metro area.

(11.9\%), and filgrastim (11.4\%) were most commonly used. Among esSCLC patients who received either carboplatin or etoposide chemotherapy, approximately 53\% received epoetin alfa and approximately $34 \%$ received filgrastim during the follow-up period. Among esSCLC patients who received topotecan, approximately $68 \%$ received epoetin alfa and $44 \%$ received filgrastim. Among mNSCLC patients who received either carboplatin or paclitaxel chemotherapy, 


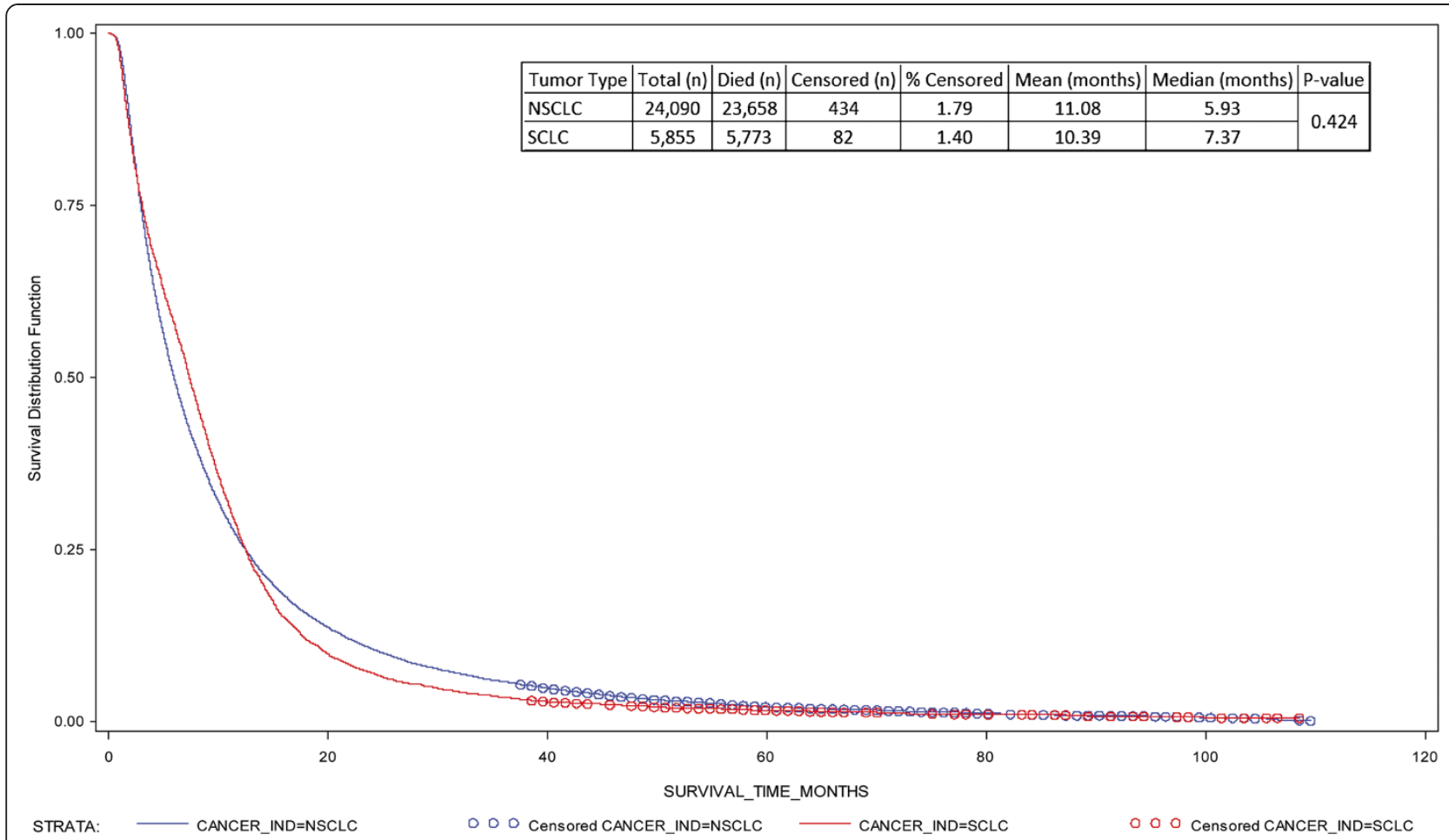

Figure 2 Kaplan-Meier survival curves, by tumor type. $\mathrm{mNSCLC}=$ metastatic non-small cell lung cancer; esSCLC= extensive-stage small cell lung cancer.

over $47 \%$ received epoetin alfa and approximately $22 \%$ received filgrastim during follow-up (tabular data available upon request).

A significantly higher proportion of esSCLC patients received other supportive therapies than did mNSCLC patients (Table 2): megestrol (38.9\% vs. $25.2 \%$; $P<0.001)$, antiemetics $(69.9 \%$ vs. $53.7 \% ; P<0.001)$, and red bloodcell $(20.7 \%$ vs. $10.9 \% ; P<0.001)$ and platelet transfusions (5.6\% vs. $1.8 \% ; P<0.001)$. mNSCLC patients received bisphosphonates with significantly greater frequency than patients with esSCLC $(9.4 \%$ vs $6.4 \% P<0.001)$. The frequency in esSCLC and mNSCLC, respectively, of antibiotics $(10.5 \%$ vs $9.7 \%$; $\mathrm{p}=0.063)$, pain medications $(23.3 \%$ vs $24.0 \% ; P=0.280$ ), and oxygen ( $29.0 \%$ vs $28.5 \% ; P=0.118$ ) utilization was similar between the two groups.

\section{Health care utilization and costs}

The percentage of patients with at least one hospitalization for any cause was high for both cohorts (esSCLC vs. mNSCLC: $91.4 \%$ vs. $88.6 \%$; $P<0.001$ ) (Table 3). Examining lung-cancer-specific hospitalizations, the frequency of post-index hospitalization was significantly higher in esSCLC patients than in mNSCLC patients $(55.9 \%$ vs. $44.9 \% ; P<0.001)$, as was average total inpatient days (mean [SD]: 7.5 [11.1] vs. 5.4 [9.3] days; $P<0.001$ ). For all other categories evaluated, disease-related health care resource utilization occurred with greater frequency for
mNSCLC patients while all-cause health care utilization was comparable between the two groups.

Per-patient total all-cause health care costs over all available follow-up among esSCLC patients exceeded those of mNSCLC patients $(\$ 70,549$ vs. $\$ 67,176 ; P<0.001)$ (Table 4). In both cohorts, hospitalization was the predominant cost driver, followed by office visits, the typical setting in which outpatient chemotherapy is administered. The mean numbers of all-cause inpatient visits (2.6 vs. 2.3; $P=0.001)$ and office visits $(44.3$ vs. $39.2 ; P<0.001)$ were higher for esSCLC patients than for mNSCLC patients. In examining disease-related costs, office visits were proportionately the largest cost driver, accounting for $43 \%$ of all disease-related costs to esSCLC patients and approximately $41 \%$ of disease-related costs to mNSCLC patients. Among esSCLC patients, total disease-related per-patient costs for all available follow-up were $16.4 \%$ higher than for mNSCLC patients $(\$ 44,167$ vs. $\$ 37,932$; $P<0.001)$. Per-month costs for esSCLC patients were $17.2 \%$ higher $(\$ 6,702$ vs. $\$ 5,721 ; P<0.001)$ than for mNSCLC patients.

\section{Discussion}

Our study confirms the substantial economic burden presented by patients with esSCLC and mNSCLC who were enrolled in the US Medicare system and who received cancer-directed treatment during 2000-2008. 
Table 2 Treatment utilization among esSCLC and mNSCLC patients, by tumor type

\begin{tabular}{|c|c|c|c|}
\hline & \multicolumn{2}{|c|}{ Study groups } & \multirow[t]{3}{*}{$P$ value } \\
\hline & esSCLC & mNSCLC & \\
\hline & $(\mathrm{N}=5,855)$ & $(\mathrm{N}=\mathbf{2 4 , 0 9 0 )}$ & \\
\hline \multicolumn{4}{|l|}{ Post-index prevalence of cancer-directed therapies } \\
\hline \multicolumn{4}{|l|}{ Overall, n (\%) ${ }^{a}$} \\
\hline Surgery & $458(7.8)$ & $3,278(13.6)$ & $<0.001$ \\
\hline Radiation therapy & $3,827(65.4)$ & $18,208(75.6)$ & $<0.001$ \\
\hline Biologic therapy & $103(1.8)$ & $282(1.2)$ & $<0.001$ \\
\hline Chemotherapy & $5,003(85.4)$ & $14,527(60.3)$ & $<0.001$ \\
\hline No. cycles received in first-line treatment, mean (SD) & $3.4(2.1)$ & $3.2(2.3)$ & \\
\hline \multicolumn{4}{|l|}{ Post-index prevalence of supportive or palliative therapies } \\
\hline \multicolumn{4}{|l|}{ Growth factors, n (\%) } \\
\hline Filgrastim/pegfilgrastim/sargramostim & $2,483(42.4)$ & $4,275(17.8)$ & $<0.001$ \\
\hline Darbepoetin/erythropoietin & $2,926(50.0)$ & $8,640(35.9)$ & $<0.001$ \\
\hline Any growth factor & $3,453(59.0)$ & $9,506(39.5)$ & $<0.001$ \\
\hline \multicolumn{4}{|l|}{ Other supportive or palliative therapies, $n(\%)^{a}$} \\
\hline Iron supplements & $39(0.7)$ & $249(1.0)$ & 0.012 \\
\hline Antibiotics & $613(10.5)$ & $2,328(9.7)$ & 0.063 \\
\hline Antiemetics & $4,095(69.9)$ & $12,947(53.7)$ & $<0.001$ \\
\hline Antifungals ${ }^{b}$ & & $21(0.1)$ & \\
\hline Pain medications & $1,366(23.3)$ & $5,782(24.0)$ & 0.280 \\
\hline Bisphosphonates & $373(6.4)$ & $2,271(9.4)$ & $<0.001$ \\
\hline Megestrol acetate & $2,276(38.9)$ & $6,078(25.2)$ & $<0.001$ \\
\hline Oxygen & $1,696(29.0)$ & $6,861(28.5)$ & 0.118 \\
\hline Red blood-cell transfusion & $1,212(20.7)$ & $2,629(10.9)$ & $<0.001$ \\
\hline Platelet transfusion & $330(5.6)$ & $426(1.8)$ & $<0.001$ \\
\hline
\end{tabular}

$\mathrm{mNSCLC}=$ non-small cell lung cancer; esSCLC $=$ small cell lung cancer.

${ }^{a}$ Categories are not mutually exclusive.

${ }^{b}$ Per National Cancer Institute protocol, data suppressed due to cell size $<11$.

All-cause and disease-related costs for esSCLC across all cost categories were at least as high and in most instances higher than for the mNSCLC cohort, with the exception of hospice and skilled nursing facility services. The primary drivers of costs for the esSCLC and mNSCLC cohorts were hospitalizations, office visits, and hospital outpatient visits.

Despite statistically significant differences between clinical and demographic characteristics, the distribution of patients in the esSCLC and mNSCLC cohorts by age, gender, race, census region, and urban versus rural status of residency at baseline were comparable. The mean age and Charlson Comorbidity Index scores were also similar. In our study, approximately $71 \%$ of patients with esSCLC initiated a first-line chemotherapy regimen of etoposide with cisplatin or carboplatin, which was considered the recommended standard regimen for esSCLC during the period studied [27-30]. A clinical trial published in 2002 reported improved survival among esSCLC patients using irinotecan plus cisplatin when compared with patients using etoposide with cisplatin [31]. However, more recent studies reported no additional survival benefit from using irinotecan-plus-cisplatin combination therapy versus etoposide-plus-cisplatin. Therefore, it was expected that utilization data from 2008 to the present may reflect different patterns compared with our data from 20002008 [32,33]. Overall, in our study, irinotecan in combination with cisplatin was the third most commonly used first-line chemotherapy regimen among esSCLC patients.

There was significant heterogeneity with esSCLC regimens used in second- and third-line therapy, reflecting the lack of standard treatment options for these settings. In our study, intravenous topotecan was the predominant regimen in both the second line $(26.3 \%)$ and the third line (20.8\%) for esSCLC patients, followed by carboplatin plus etoposide (18.1\% of second-line initiators, $11.7 \%$ of third- 


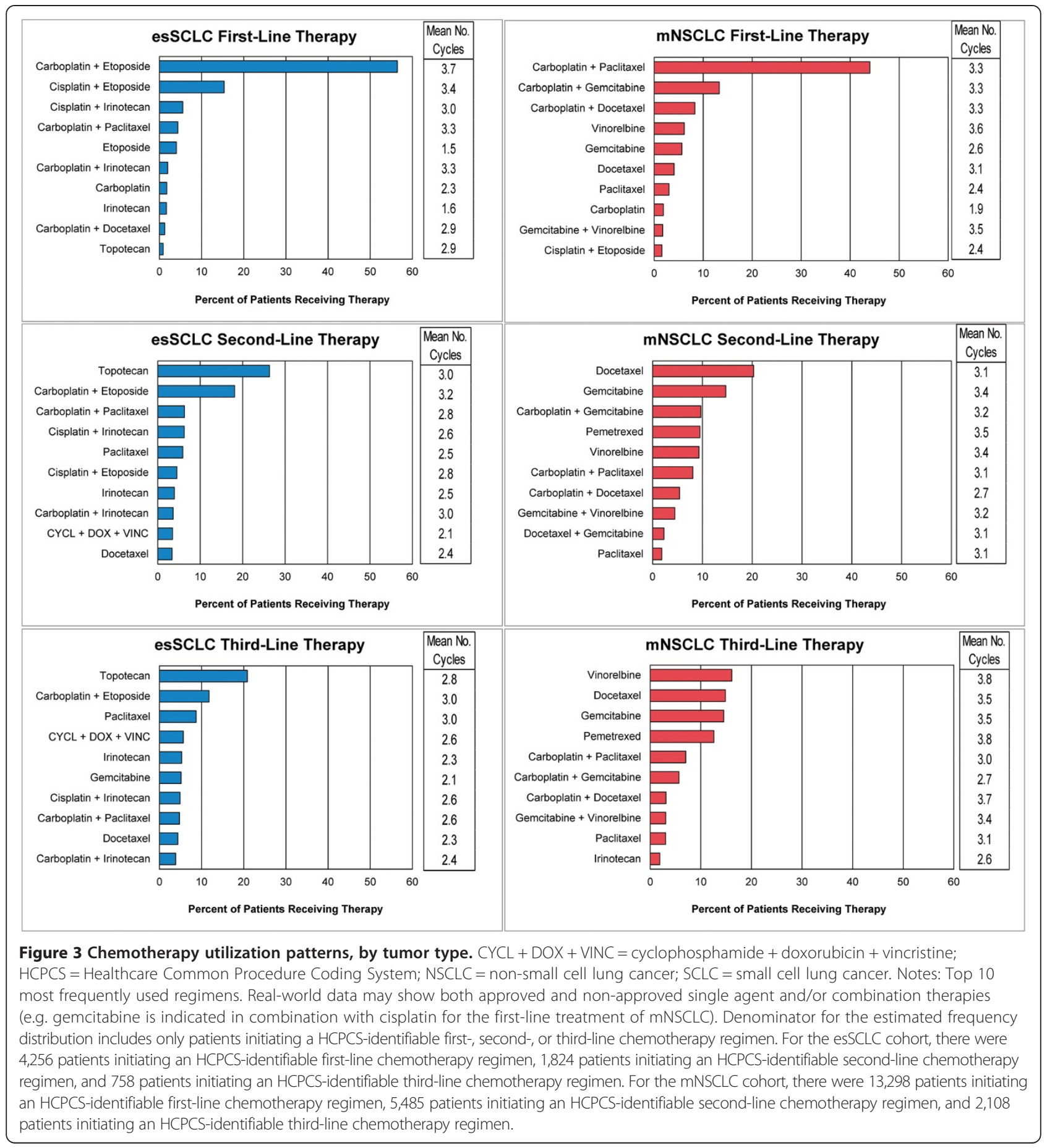

line initiators). Intravenous topotecan is the only therapy approved by the US Food and Drug Administration (FDA) for platinum-sensitive esSCLC patients after failure of first-line therapy, despite demonstrating nonsignificant differences in efficacy outcomes when compared with cyclophosphamide, doxorubicin, and vincristine [34]. The relatively high usage of these therapies, with lack of improved survival outcomes from the registration trial, may reflect the greater need for and lack of impactful treatment alternatives for esSCLC patients. The US FDA also approved oral topotecan for patients with relapsed esSCLC on the basis of significantly improved differences in overall survival versus best supportive care (log-rank: $P=0.0104$ ) [35]. Because of limited claims data from the Medicare Part D program, we were not able to capture the use of oral topotecan, but this information has 
Table 3 Overall health care utilization among esSCLC and mNSCLC patients, by tumor type

\begin{tabular}{|c|c|c|c|}
\hline & \multicolumn{2}{|l|}{ Study groups } & \multirow[t]{3}{*}{$P$ value } \\
\hline & esSCLC & mNSCLC & \\
\hline & $(\mathrm{N}=5,855)$ & $(\mathrm{N}=\mathbf{2 4 , 0 9 0 )}$ & \\
\hline \multicolumn{4}{|l|}{ Hospitalizations } \\
\hline \multicolumn{4}{|l|}{ All cause } \\
\hline $\mathrm{Had} \geq 1$ admission, $\mathrm{n}(\%)$ & $5,349(91.36)$ & 21,351 (88.63) & $<0.001$ \\
\hline Mean (SD) number of admissions & $2.56(2.16)$ & $2.28(1.96)$ & 0.001 \\
\hline Mean (SD) total days in hospital & $17.79(17.37)$ & $16.40(17.34)$ & $<0.001$ \\
\hline \multicolumn{4}{|l|}{ Disease related } \\
\hline Had $\geq 1$ admission, $n(\%)$ & $3,272(55.88)$ & $10,825(44.94)$ & $<0.001$ \\
\hline Mean (SD) number of admissions & $0.91(1.25)$ & $0.61(0.86)$ & $<0.001$ \\
\hline Mean (SD) total days in hospital & $7.47(11.09)$ & $5.40(9.31)$ & $<0.001$ \\
\hline \multicolumn{4}{|l|}{ ER visits } \\
\hline \multicolumn{4}{|l|}{ All cause } \\
\hline Had $\geq 1$ visit, $\mathrm{n}(\%)$ & $4,850(82.84)$ & $19,393(80.50)$ & $<0.001$ \\
\hline Mean (SD) number of visits & $2.32(2.38)$ & $2.20(2.36)$ & $<0.001$ \\
\hline \multicolumn{4}{|l|}{ Disease related } \\
\hline Had $\geq 1$ visit, $\mathrm{n}(\%)$ & 2,295 (39.20) & $9,145(37.96)$ & 0.081 \\
\hline Mean (SD) number of visits & $0.54(1.05)$ & $0.66(1.17)$ & 0.003 \\
\hline \multicolumn{4}{|l|}{ Office visits } \\
\hline \multicolumn{4}{|l|}{ All cause } \\
\hline Had $\geq 1$ visit, $\mathrm{n}(\%)$ & $5,789(98.87)$ & 23,764 (98.65) & 0.172 \\
\hline Mean (SD) number of visits & $44.27(43.57)$ & $39.18(43.79)$ & $<0.001$ \\
\hline \multicolumn{4}{|l|}{ Disease-related } \\
\hline Had $\geq 1$ visit, $n(\%)$ & $5,527(94.40)$ & 22,915 (95.12) & 0.023 \\
\hline Mean (SD) number of visits & $22.93(31.00)$ & $31.82(32.93)$ & $<0.001$ \\
\hline \multicolumn{4}{|l|}{ Hospital outpatient visits } \\
\hline \multicolumn{4}{|l|}{ All cause } \\
\hline Had $\geq 1$ visit, $\mathrm{n}(\%)$ & $5,320(90.86)$ & $22,018(91.40)$ & 0.192 \\
\hline Mean (SD) number of visits & $13.05(16.69)$ & $12.18(16.78)$ & $<0.001$ \\
\hline \multicolumn{4}{|l|}{ Disease related } \\
\hline Had $\geq 1$ visit, $\mathrm{n}(\%)$ & $4,846(82.77)$ & $19,881(82.53)$ & 0.666 \\
\hline Mean (SD) number of visits & $6.47(11.35)$ & $8.97(12.65)$ & $<0.001$ \\
\hline \multicolumn{4}{|l|}{ Hospice visits } \\
\hline \multicolumn{4}{|l|}{ All cause } \\
\hline Had $\geq 1$ visit, $\mathrm{n}(\%)$ & 3,091 (52.79) & $12,982(53.89)$ & 0.131 \\
\hline Mean (SD) number of visits & $1.17(2.12)$ & $1.30(2.57)$ & $<0.001$ \\
\hline \multicolumn{4}{|l|}{ Disease related } \\
\hline Had $\geq 1$ visit, $\mathrm{n}(\%)$ & 2,927 (49.99) & $12,104(50.24)$ & 0.728 \\
\hline Mean (SD) number of visits & $1.04(2.22)$ & $1.10(2.05)$ & $<0.001$ \\
\hline \multicolumn{4}{|l|}{ Skilled nursing facility care } \\
\hline \multicolumn{4}{|l|}{ All cause } \\
\hline Had $\geq 1$ visit, $\mathrm{n}(\%)$ & $1,497(25.57)$ & $6,171(25.62)$ & 0.939 \\
\hline Mean (SD) number of visits & $0.37(0.79)$ & $0.37(0.77)$ & 0.652 \\
\hline
\end{tabular}


Table 3 Overall health care utilization among esSCLC and mNSCLC patients, by tumor type (Continued)

\begin{tabular}{|c|c|c|c|}
\hline \multicolumn{4}{|l|}{ Disease related } \\
\hline Had $\geq 1$ visit, $n(\%)$ & $1,211(20.68)$ & $4,829(20.05)$ & 0.276 \\
\hline Mean (SD) number of visits & $0.24(0.60)$ & $0.28(0.66)$ & 0.026 \\
\hline \multicolumn{4}{|l|}{ Ancillary care } \\
\hline \multicolumn{4}{|l|}{ All cause } \\
\hline Had $\geq 1$ visit, $\mathrm{n}(\%)$ & $4,070(69.51)$ & $16,455(68.31)$ & 0.075 \\
\hline Mean (SD) number of visits & $5.94(10.07)$ & $5.62(11.14)$ & 0.049 \\
\hline \multicolumn{4}{|l|}{ Disease related } \\
\hline $\mathrm{Had} \geq 1$ visit, $\mathrm{n}(\%)$ & $3,035(51.84)$ & $11,793(48.95)$ & $<0.001$ \\
\hline Mean (SD) number of visits & $1.96(4.58)$ & $2.65(5.25)$ & $<0.001$ \\
\hline
\end{tabular}

recently become available via the SEER-Medicare data program.

Approximately $40 \%$ of patients in the mNSCLC cohort and $60 \%$ of patients in the esSCLC cohort received either an erythropoietic therapy (ESA) or myeloid growth factor during the follow-up period. Pegfilgrastim, filgrastim, and sargramostim use was $42.4 \%$ across lines of therapy among esSCLC patients, and use was significantly greater than patients with mNSCLC (17.8\%). Darbepoetin/ erythropoietin use was also fairly high across both esSCLC (50\%) and mNSCLC (35.9\%) cohorts. A high rate of growth-factor use $(>50 \%)$ in the real-world setting has been reported previously, despite low support of its use by the American Society of Clinical Oncology [36]. According to current guidelines by the National Comprehensive Cancer Network (NCCN), use of myeloid growth factor is not routinely recommended for primary prophylaxis in esSCLC or mNSCLC patients receiving chemotherapy. However, such therapy is recommended and should be considered after risk factor assessment in patients who are at high $(>20 \%)$ or intermediate $(10 \%$ $20 \%$ ) risk for developing febrile neutropenia. NCCN strongly prefers that a less myelosuppressive therapy be used or dose reductions be considered so long as efficacy outcomes are not compromised [37]. NCCN guidelines that were in place during the observation period of our study reflect these same considerations [38].

Guidelines for ESA use evolved from 2002 to 2008 due to the increasing knowledge over time regarding safety of these agents. Prior to 2007, the guidelines recommended ESAs in an effort to avoid transfusions and improve patient quality of life. However, since that time an increasing amount of data became available outlining the thrombosis risk and potential negative impact on patient survival. This not only prompted black box warnings by FDA for these agents, but changed the guideline recommendation in 2008 to exclude use in patients who could be cured of their disease. Additonally, the hemaglobin target was lowered from twelve to ten grams per deciliter. The 2008 guideline also communicated the thrombosis and mortality risk associated with blood transfusions, and urged patients to thoroughly discuss the risks and benefits of both ESA use and/or blood transfusions with their physician [39].

The availability of data outlining concerns associated with ESA use, black box warnings, and changes in treatment recommendations all occurred during the latter portion of our study period. We did not conduct a trend

Table 4 Mean all-cause and disease-related health care costs among esSCLC and mNSCLC patients, by tumor type

\begin{tabular}{|c|c|c|c|c|c|c|}
\hline & \multicolumn{2}{|l|}{ All cause } & \multicolumn{2}{|c|}{ Disease-related } & \multicolumn{2}{|l|}{ esSCLC vs. mNSCLC } \\
\hline & esSCLC (\$) & $\operatorname{mNSCLC}(\$)$ & esSCLC (\$) & mNSCLC (\$) & $P$ value (All-cause costs) & $P$ calue (Disease-related costs) \\
\hline Hospitalizations & 32,456 & 32,027 & 12,498 & 9,778 & 0.403 & $<0.001$ \\
\hline Office Visits & 22,340 & 18,995 & 19,168 & 15,622 & $<0.001$ & $<0.001$ \\
\hline Hospital OP Visits & 7,253 & 7,040 & 6,044 & 5,767 & 0.270 & 0.116 \\
\hline Hospice & 3,099 & 3,693 & 2,933 & 3,419 & $<0.001$ & $<0.001$ \\
\hline Other Ancillary Care & 2,624 & 2,502 & 1,656 & 1,495 & 0.086 & 0.001 \\
\hline Skilled Nursing Facility & 2,453 & 2,607 & 1,790 & 1,775 & 0.111 & 0.846 \\
\hline ER Visits & 324 & 312 & 78 & 76 & 0.022 & 0.389 \\
\hline Total & 70,549 & 67,176 & 44,167 & 37,932 & $<0.001$ & $<0.001$ \\
\hline
\end{tabular}

$\mathrm{ER}=$ emergency department; $\mathrm{mNSCLC}=$ metastatic non-small cell lung cancer; $\mathrm{OP}$ = outpatient; es $\mathrm{SCLC}=$ extensive-stage small cell lung cancer. 
analysis evaluating use over time of either myeloid factors or ESAs given that our observation period ended in 2008; this did not allow enough time to observe a meaningful trend. Further research is warranted in the esSCLC and mNSCLC populations to characterize the trajectory of this information over time. These data suggest that use of ESAs did indeed decrease over time due to changing guidelines as well as subsequent reimbursement stipulations [40]. While the assessment of side effects associated with chemotherapy was beyond the scope of this project, the higher use of chemotherapy among esSCLC patients $(85.5 \%)$ than mNSCLC patients $(60.3 \%)$ could have contributed to a higher rate of side effects (e.g., chemotherapy-induced nausea and vomiting), resulting in greater use of supportive care therapies, greater health care utilization, and associated costs [41,42]. In addition to growth factor use, there was significantly greater use of antiemetics and megesterol acetate; as well as $\mathrm{RBC}$ and platelet tranfusions in patients with esSCLC. Additionally, a greater proportion of esSCLC patients had at least one hospitalization and spent on average 1.5 days longer in the hospital. These findings may be a reflection of the negative sequelae that can be associated with chemotherapy use (and its more significant use among esSCLC patients) and may also reflect the aggressiveness of esSCLC. Further research is necessary to assess the costs associated with chemotherapy-related side effects for esSCLC and mNSCLC patients [43].

Among mNSCLC patients, we found that $75.6 \%$ received radiation which is recommended as palliation according to NCCN [44], and to help prevent symptoms due to primary or metastatic tumors. In our study, approximately two-thirds of mNSCLC patients initiating chemotherapy received carboplatin in combination with paclitaxel, docetaxel, or gemcitabine; this is consistent with prior research and recommendations during the time period of our study [45-48], but may not always match the product labels. It is important to note that more recent advancements in mNSCLC are not fully captured in our data, either because there was minimal time from the availabilty of a new therapy to the end of our observation period or because therapies were approved after the end of our study period. This includes the US FDA approvals for bevacizumab, erlotinib, pemetrexed, nab-paclitaxel, afatinib, gefitinib, crizotinib, and ceritinib. This is a significant limitation of the generalizability of mNSCLC treatment pattern data in our study to current practice.

The lack of oral prescription drug data (i.e., Medicare Part D) in our study further contributed to the conservative nature of our cost estimates and limited our ability to gain information relative to erlotinib and topotecan use in mNSCLC patients and esSCLC patients, respectively. We recommend that these analyses be updated now that these claim data are available.
A few additional limitations must be considered when interpreting these study findings. First, our analysis did not include clinical trial participants or patients receiving only supportive care; this likely underestimated the total economic burden of esSCLC and mNSCLC. Second, our definition of lung-cancer-specific treatment (chemotherapy, radiation) was based on HCPCS and ICD-9-CM diagnosis and procedure codes; any coding inaccuracies could lead to misclassification of these treatments. Third, our method of estimating disease-related costs accounted only for adjudicated medical claims carrying a lung-cancer diagnosis code or claim for treatments and procedures (chemotherapy, surgery, radiation) that were likely to be cancer related. This microcosting approach likely understates the true direct costs to Medicare of lung-cancer management because other treatments and other medical services not considered in the definition are likely to be utilized in the management of the disease. We therefore also assessed all-cause resource utilization, which likely overstated actual costs. Fourth, this analysis was limited to elderly Medicare enrollees with distant-stage lung cancer. While this is the subpopulation in which lung cancer occurs most often, our results may not be generalizable to younger adults, individuals enrolled in other federal or commercial health plans, individuals without health coverage, or individuals with localized- or regional-stage lung cancer. Finally, while this study was conducted using the most up-to-date SEER-Medicare data at the time, more recent data are now available. As noted above, while this is a significant limitation in terms of the mNSCLC treatment pattern data, it is not believed to be a limitation to the accuracy of the cost and HCRU data. Since there have been no recent advancements in the treatment of esSCLC, the data used in this study remain representative and informative with regard to real-world treatment patterns, costs, and survival in these patients.

\section{Conclusion}

In conclusion, our study demonstrated that the direct medical costs of both esSCLC and mNSCLC are substantial and comparable; with a growing elderly population, this cost burden to the Medicare system will increase in the future. Additionally, therapies that provide clinically meaningful improvements in efficacy, safety, and less frequent dosing may help lower treatment-specific and future downstream costs. In contrast to mNSCLC, distant-stage esSCLC has had few therapies introduced that have advanced overall survival, thus underscoring the unmet need in this particular population of patients with lung cancer. Overall, the similar survival estimates and the significant per-patient lifetime costs for esSCLC and metastatic mNSCLC underscore the unmet medical need for patients with these tumor types. Our study findings complement existing literature and may help 
researchers and policy makers by providing support and model inputs to Medicare-based cost-effectiveness studies of interventions focused on prevention of lung cancer or prevention of progression to the advanceddisease stage.

\section{Additional file}

Additional file 1: Procedure and diagnosis codes used to identify cancer-directed and supportive therapies.

\section{Competing interests}

Keith Davis is an employee and Sudeep Karve is a former employee of RTI Health Solutions, an independent contract research organization that has received research funding from Eli Lilly and Company (Lilly) for this study. Greg Price, Gerhardt Pohl, Emily Nash Smyth, and Lee Bowman are employees of Lilly. The manuscript underwent scientific quality and legal review by Lilly prior to submission. Final decisions regarding manuscript content were made jointly by the authors.

\section{Authors information}

SJ Karve was an employee of RTI Health Solutions at the time this study was conducted.

\section{Authors' contributions}

KD, SK, GP, and GP were the primary developers of the study design. As principal investigator, Sudeep Karve had full access to all the data in the study and takes responsibility for the integrity of the data and the accuracy of the data analysis. KD and SK led all statistical analyses. SK also served as the primary writer in drafting the manuscript text and in interpreting the findings. GP, GP, ENS and LB assisted in interpreting the study findings and drafting the manuscript text; they also served as the primary reviewers of the manuscript text. All authors were responsible for approving the manuscript and its contents.

\section{Author details}

${ }^{1}$ RTI Health Solutions, 3040 Cornwallis Road, Research Triangle Park, Durham, NC 27709, USA. ${ }^{2}$ Eli Lilly and Company, Lilly Corporate Center, Indianapolis, IN 46285, Indian.

Received: 29 August 2013 Accepted: 24 October 2014

Published online: 13 November 2014

\section{References}

1. Siegel R, MA J, Zou Z, Jemal A: Cancer statistics. CA Cancer J Clin 2014, 64:9-29.

2. Howlader N, Noone AM, Krapcho M, Neyman N, Aminou R, Waldron W, Altekruse SF, Kosary CL, Ruhl J, Tatalovich Z, Cho H, Mariotto A, Eisner MP, Lewis DR, Chen HS, Feuer EJ, Cronin KA, Edwards BK: SEER Cancer Statistics Review: 1975-2008. [http://seer.cancer.gov/csr/1975_2008/]

3. National Comprehensive Cancer Network: NCCN Guidelines for Patients: Non-small Cell Lung Cancer. Version 1. 2014. [http://www.nccn.org/ patients/guidelines/nscl/\#1]

4. Kalemkerian GP, Akerley W, Bogner P, Borghaei $H$, Chow L, Downey RJ, Gandhi L, Ganti AK, Govindan R, Grecula JC, Hayman J, Heist RS, Horn L, Jahan TM, Koczywas M, Moran CA, Niell HB, O'Malley J, Patel JD, Ready N, Rudin CM, Williams CC Jr, National Comprehensive Cancer Network: Small cell lung cancer. J Natl Compr Canc Netw 2011, 9:1086-1113.

5. Mariotto AB, Yabroff KR, Shao Y, Feuer EJ, Brown ML: Projections of the cost of cancer care in the United States: 2010-2020. J Natl Cancer Inst 2011, 103:117-128.

6. Graham P, Boyages J: Economic and quality-of-life aspects of treating small cell lung cancer. Pharmacoeconomics 1993, 3:446-453.

7. Rosenthal MA, Webster PJ, Gebeski VJ, Stuart-Harris RC, Langlands AO, Boyages J: The cost of treating small cell lung cancer. Med J Aust 1992, 156:605-610.

8. Carlson JJ, Reyes C, Oestreicher N, Lubeck D, Ramsey SD, Veenstra DL: Comparative clinical and economic outcomes of treatments for refractory non-small cell lung cancer (mNSCLC). Lung Cancer 2008 , 61:405-415.

9. Hoverman JR, Robertson SM: Lung cancer: a cost and outcome study based on physician practice patterns. Dis Manag 2004, 7:112-123.

10. Lang K, Marciniak MD, Faries D, Stokes M, Buesching D, Earle C, Treat J, Babineaux S, Morissette N, Thompson D: Costs of first-line doublet chemotherapy and lifetime medical care in advanced non-small-cell lung cancer in the United States. Value Health 2009, 12:481-488.

11. Chang S, Long SR, Kutikova L, Bowman L, Finley D, Crown WH, Bennett CL: Estimating the cost of cancer: results on the basis of claims data analyses for cancer patients diagnosed with seven types of cancer during 1999-2000. J Clin Oncol 2004, 22:3524-3530.

12. Kutikova L, Bowman L, Chang S, Long SR, Obasaju C, Crown WH: The economic burden of lung cancer and the associated costs of treatment failure in the United States. Lung Cancer 2005, 50:143-154.

13. Ramsey SD, Martins RG, Blough DK, Tock LS, Lubeck D, Reyes CM: Second-line and third-line chemotherapy for lung cancer: use and cost. Am J Manag Care 2008, 14:297-306.

14. Davidoff AJ, Tang M, Seal B, Edelman MJ: Chemotherapy and survival benefit in elderly patients with advanced non-small-cell lung cancer. J Clin Oncol 2010, 28:2191-2197.

15. Duh MS, Reynolds Weiner J, Lefebvre P, Neary M, Skarin AT: Costs associated with intravenous chemotherapy administration in patients with small cell lung cancer: a retrospective claims database analysis. Curr Med Res Opin 2008, 24:967-974.

16. Stokes ME, Muehlenbein CE, Marciniak MD, Faries DE, Motabar S, Gillespie TW Lipscomb J, Knopf KB, Buesching DP: Neutropenia-related costs in patients treated with first-line chemotherapy for advanced non-small cell lung cancer. J Manag Care Pharm 2009, 15:669-682.

17. Ramsey SD, Howlader N, Etzioni RD, Donato B: Chemotherapy use, outcomes, and costs for older persons with advanced non-small-cell lung cancer: evidence from surveillance, epidemiology and end results-Medicare. $J$ Clin Oncol 2004, 22:4971-4978.

18. Cipriano LE, Romanus D, Earle CC, Neville BA, Halpern EF, Gazelle GS, McMahon PM: Lung cancer treatment costs, including patient responsibility, by disease stage and treatment modality, 1992 to 2003. Value Health 2011, 14:41-52.

19. National Cancer Institute: SEER Fact Sheets and Brochures. [http://seer. cancer.gov/about/factsheets/SEER_brochure.pdf]

20. Govindan R, Page N, Morgensztern D, Read W, Tierney R, Vlahiotis A Spitznagel EL, Piccirillo J: Changing epidemiology of small-cell lung cancer in the United States over the last 30 years: analysis of the surveillance, epidemiologic, and end results database. J Clin Oncol 2006, 24:4539-4544.

21. Young $J \mathrm{~L} J \mathrm{r}$, Roffers SD, Ries LAG, Fritz AG, Hurlbut AA: SEER Summary Staging Manual-2000: Codes and Coding Instructions. In Bethesda, MD, National Cancer Institute, NIH publication No. 01-4969, 2001, NIH publication No. 01-4969. Bethesda, MD: National Cancer Institute; 2001.

22. Hershman D, Hall MJ, Wang X, Jacobson JS, McBride R, Grann VR, Neugut Al: Timing of adjuvant chemotherapy initiation after surgery for stage III colon cancer. Cancer 2006, 107:2581-2588.

23. Sundararajan V, Hershman D, Grann VR, Jacobson JS, Neugut Al: Variations in the use of chemotherapy for elderly patients with advanced ovarian cancer: a population-based study. J Clin Oncol 2002, 20:173-178.

24. Quan H, Sundararajan V, Halfon P, Fong A, Burnand B, Luthi JC, Saunders LD, Beck CA, Feasby TE, Ghali WA: Coding algorithms for defining comorbidities in ICD-9-CM and ICD-10 administrative data. Med Care 2005, 43:1130-1139.

25. Weycker D, Malin J, Kim J, Barron R, Edelsberg J, Kartashov A, Oster G: Risk of hospitalization for neutropenic complications of chemotherapy in patients with primary solid tumors receiving pegfilgrastim or filgrastim prophylaxis: a retrospective cohort study. Clin Ther 2009, 31:1069-1081.

26. Heaney ML, Toy EL, Vekeman F, Laliberté F, Dority BL, Perlman D, Barghout V, Duh MS: Comparison of hospitalization risk and associated costs among patients receiving sargramostim, filgrastim, and pegfilgrastim for chemotherapy-induced neutropenia. Cancer 2009, 115:4839-4848.

27. Heigener DF, Manegold C, Jäger E, Saal JG, Zuna I, Gatzemeier U: Multicenter randomized open-label phase III study comparing efficacy, safety, and tolerability of conventional carboplatin plus etoposide versus dose-intensified carboplatin plus etoposide plus lenograstim in small-cell lung cancer in "extensive disease" stage. Am J Clin Oncol 2009, 32:61-64.

28. Jiang J, Liang X, Zhou X, Huang L, Huang R, Chu Z, Zhan Q: A metaanalysis of randomized controlled trials comparing irinotecan/platinum 
with etoposide/platinum in patients with previously untreated extensive-stage small cell lung cancer. J Thorac Oncol 2010, 5:867-873.

29. Mascaux C, Paesmans M, Berghmans T, Branle F, Lafitte JJ, Lemaitre F, Meert AP, Vermylen P, Sculier JP: European Lung Cancer Working Party (ELCWP); European Lung Cancer Working Party (ELCWP): A systematic review of the role of etoposide and cisplatin in the chemotherapy of small cell lung cancer with methodology assessment and meta-analysis. Lung Cancer 2000, 30:23-36.

30. Okamoto H, Watanabe K, Kunikane H, Yokoyama A, Kudoh S, Asakawa T, Shibata T, Kunitoh H, Tamura T, Saijo N: Randomised phase III trial of carboplatin plus etoposide vs split doses of cisplatin plus etoposide in elderly or poor-risk patients with extensive disease small-cell lung cancer: JCOG 9702. Br J Cancer 2007, 97:162-169.

31. Noda K, Nishiwaki Y, Kawahara M, Negoro S, Sugiura T, Yokoyama A, Fukuoka M, Mori K, Watanabe K, Tamura T, Yamamoto S, Saijo N, Japan Clinical Oncology Group; Japan Clinical Oncology Group: Irinotecan plus cisplatin compared with etoposide plus cisplatin for extensive small-cell lung cancer. N Engl J Med 2002, 346:85-91.

32. Hanna N, Bunn PA Jr, Langer C, Einhorn L, Guthrie T Jr, Beck T, Ansari R, Ellis P, Byrne M, Morrison M, Hariharan S, Wang B, Sandler A: Randomized phase III trial comparing irinotecan/cisplatin with etoposide/cisplatin in patients with previously untreated extensive-stage disease small-cell lung cancer. J Clin Oncol 2006, 24:2038-2043.

33. Lara PN Jr, Natale R, Crowley J, Lenz HJ, Redman MW, Carleton JE, Jett J, Langer CJ, Kuebler JP, Dakhil SR, Chansky K, Gandara DR: Phase III trial of irinotecan/cisplatin compared with etoposide/cisplatin in extensivestage small-cell lung cancer: clinical and pharmacogenomic results from SWOG S0124. J Clin Oncol 2009, 27:2530-2535.

34. von Pawel J, Schiller JH, Shepherd FA, Fields SZ, Kleisbauer JP, Chrysson NG, Stewart DJ, Clark Pl, Palmer MC, Depierre A, Carmichael J, Krebs JB, Ross G, Lane SR, Gralla R: Topotecan versus cyclophosphamide, doxorubicin, and vincristine for the treatment of recurrent small-cell lung cancer. J Clin Oncol 1999, 17:658-667.

35. O'Brien ME, Ciuleanu TE, Tsekov H, Shparyk Y, Cuceviá B, Juhasz G, Thatcher N, Ross GA, Dane GC, Crofts T: Phase III trial comparing supportive care alone with supportive care with oral topotecan in patients with relapsed small-cell lung cancer. J Clin Oncol 2006, 24:5441-5447.

36. Adams JR, Lyman GH, Djubegovic B, Feinglass J, Bennett CL: G-CSF as prophylaxis of febrile neutropenia in SCLC. Expert Opin Pharmacother 2002, 3:1273-1281

37. National Comprehensive Cancer Network: Clinical Practice Guidelines in Oncology (NCCN guidelines): Myeloid Growth Factors, Version I. 2012.

38. Lyman GH, Kleiner JM: Summary and comparison of myeloid growth factor guidelines in patients receiving cancer chemothearpy. JCCN 2007, 5:217-228.

39. Rodgers GM: A perspective on the evolution of management of cancer- and chemotherapy-induced anemia. J Natl Compr Canc Netw 2012, 10:434-437.

40. Shapira I, Raftopoulos H, Gralla RJ, Pelc K, Gleason K: The impact of randomized trial results and altered regulatory policies on ESA use, transfusions, and thrombosis: A longitudinal analysis over a 3-year period of resource utilization data from a large comprehensive oncology program. ASCO Annu Meet Proc 2009, 27(15S):6611.

41. Cohen L, de Moor CA, Eisenberg P, Ming EE, Hu H: Chemotherapy-induced nausea and vomiting: incidence and impact on patient quality of life at community oncology settings. Support Care Cancer 2007, 15:497-503.

42. Glaus A, Knipping C, Morant R, Böhme C, Lebert B, Beldermann F, Glawogger B, Ortega PF, Hüsler A, Deuson R: Chemotherapy-induced nausea and vomiting in routine practice: a European perspective. Support Care Cancer 2004, 12:708-715.

43. Clegg A, Scott DA, Sidhu M, Hewitson P, Waugh N: A rapid and systematic review of the clinical effectiveness and cost-effectiveness of paclitaxel, docetaxel, gemcitabine and vinorelbine in non-small-cell lung cancer. Health Technol Assess 2001, 5:1-195.

44. National Comprehensive Cancer Network: Clinical Practice Guidelines in Oncology (NCCN guidelines): Non-Small Cell Lung Cancer. 2012.

45. Azzoli CG, Baker S Jr, Temin S, Pao W, Aliff T, Brahmer J, Johnson DH, Laskin J, Masters G, Milton D, Nordquist L, Pfister DG, Piantadosi S, Schiller JH, Smith R, Smith TJ, Strawn JR, Trent D, Giaccone G, American Society of Clinical Oncology: American Society of Clinical Oncology Clinical Practice
Guideline update on chemotherapy for stage IV non-small-cell lung cancer. J Clin Oncol 2009, 27:6251-6266.

46. Chu Q, Vincent M, Logan D, Mackay JA, Evans WK, Lung Cancer Disease Site Group of Cancer Care Ontario's Program in Evidence-based Care; Lung Cancer Disease Site Group of Cancer Care Ontario's Program in Evidencebased Care: Taxanes as first-line therapy for advanced non-small cell lung cancer: a systematic review and practice guideline. Lung Cancer 2005, 50:355-3574.

47. Le Chevalier T, Scagliotti G, Natale R, Danson S, Rosell R, Stahel R, Thomas P, Rudd RM, Vansteenkiste J, Thatcher N, Manegold C, Pujol JL, van Zandwijk N, Gridelli C, van Meerbeeck JP, Crino L, Brown A, Fitzgerald P, Aristides M, Schiller JH: Efficacy of gemcitabine plus platinum chemotherapy compared with other platinum containing regimens in advanced non-small-cell lung cancer: a meta-analysis of survival outcomes. Lung Cancer 2005, 47:69-80.

48. Pujol JL, Barlesi F, Daurès JP: Should chemotherapy combinations for advanced non-small cell lung cancer be platinum-based? A metaanalysis of phase III randomized trials. Lung Cancer 2006, 51:335-345.

\section{doi:10.1186/s12913-014-0555-8}

Cite this article as: Karve et al:: Comparison of demographics, treatment patterns, health care utilization, and costs among elderly patients with extensive-stage small cell and metastatic non-small cell lung cancers. BMC Health Services Research 2014 14:555.

\section{Submit your next manuscript to BioMed Central and take full advantage of:}

- Convenient online submission

- Thorough peer review

- No space constraints or color figure charges

- Immediate publication on acceptance

- Inclusion in PubMed, CAS, Scopus and Google Scholar

- Research which is freely available for redistribution
( Biomed Central 